\title{
MANUFACTURABILITY VERIFICATION AND COMPARISON OF QUALITY PARAMETERS OF SHAPED SURFACE
}

\author{
Miroslav Tomás $\check{s}^{1)}$, Dagmar Draganovska ${ }^{l)}$, Juraj Hudák $k^{l)}$, Peter Ižol ${ }^{1)}$ \\ 1) Technical University of Košice, Faculty of Mechanical Engineering,Košice, Slovakia
}

Received: 14.10 .2013

Accepted: 18.12.2013

Corresponding author: e-mail address: miroslav.tomas@tuke.sk, Tel.: +421 556023524 , Department of Technologies and Material, Faculty of Mechanical Engineering, Technical University of Košice, Mäsiarska 74, 04200 Košice, Slovakia

\begin{abstract}
The paper describes stamping punch production from the view manufacturability and quality of stamping punch active surfaces. The tin car-body stamping punch has been chosen as a subject of experimental work. The experimental stamping punch has been made out of Textit and production stamping punch has been made out of tool steel X210Cr12. Milling strategies has been proposed and verified using CAM software SolidCAM considering the maximum Scallop Height. The roughness parameters $\mathrm{Ra}$ and $\mathrm{Rz}$ measured on selected areas of stamping punch shaped surface were compared to Scallop Height. Manufactured areas on shaped surface were optically evaluated as well. The application of proposed procedure is shown as an example of manufacturability for experimental and production stamping punch designed for complex parts production.
\end{abstract}

Keywords: tool steel, stamping, simulation

\section{Introduction}

Components with shaped surfaces are made by various technological processes, whereby their form is frequently obtained in the direct contact with a production device - a forging die, forming die, a form for die-casting or an injection molding tools for plastic materials. The shapecomplicated surfaces are often on such component parts from which complex shapes of forming tools and dies are derived. By reason of high costs for forming tools and dies, the design of a suitable technological process is the key factor.

In the production of tools and dies, giving their shape to manufactured components, it is frequently necessary to put contradictory requirements into accordance e.g. the production time minimizing in achieving of the required accuracy of dimensions and a surface quality. In such cases, the implied technology of a device production represents the significant role. If a forming tool was manufactured by machining and cutting technologies, it would be necessary to also deal with appropriate strategies. In CAM system, the notion strategy of machining presents predefined tracks of a tool, optimized for machining of various shape surfaces to make a product in the most effective way. The selection of proper machining strategy is often a main task of the production process.

The aim of the described activities was to manufacture a stamping punch of a testing and subsequently also production die for pressing of a model automobile car body, which was created within the framework of a project SteelPARK - Creative factory. The project is focused 
on the popularization of science and technology, mainly among young people [1]. The testing stamping die was used for a verification of suggested production process, the production of testing models series and to particularize suggested parameters of deep-drawing. The experience obtained from the production of the testing device was used for manufacturing of the production stamping die. The measurements of the surface roughness at various areas of a shape surface and the documented surface topography were subsequently done on the both pressings.

In manufacturing of surface areas by machining on milling machines the copy cutter is used in a finishing process in most of the cases. That cutting device removes an additional material along created paths and leaves excess material in the form of scallops (undulations) between adjacent tracks of the tool. Because the height of scallops defines a surface roughness and affects also a dimensional accuracy, therefore it is required for it to obtain the lowest values as possible. The height of scallops is possible to decrease by a higher density of the tool tracks and by using a tool with a bigger diameter. The shaped surfaces created by milling are usually finished by the hand-operated processes in order to remove traces after milling and to reach the smooth surface. The task for NC programmers is to define such a density of a milling cutter which will set manufacturing periods of time and costs of both the operations - the milling operation and the hand-operated finishing process - at the lowest level as possible. One of the solutions is a creation of such traces of devices which will ensure the constant height of undulations, so called iso-cusped tool paths, by which the hand-operated finishing process will be more effective. The description of various process is stated e.g. in [2]. In that source a possible process to obtain such traces is also stated whereby the height of undulations is presented from values of given surfaces tolerations. The critical surface roughnesses are defined in [3] for the finishing operation to reach the minimal time. Description of the surface finishing method is presented in [4] as well.

The current selection methods of suitable strategies still require responsible decisions of a technologist - an NC programmer, e.g. in the before mentioned selection of a tool parameter or the setting of distances between adjacent traces of a device. Excessively big diameter of a milling tool does not allow an access to some areas for a work-piece, a small diameter of a tool invokes the necessity to increase the number of junctions on a machined surface. If spacing between the traces is too big, the result is an increased roughness of a surface, on the contrary by the decreasing of the spacing the time for machining is increased. For the solution of that problem e.g. the authors [5] suggested the analytical method for CNC machining of shape surfaces, based on the five steps: the detection of a surface equation, the curving analysis, the selection of tools, the calculation of deviations between a required and obtained surface and the calculation itself of the distance between adjacent traces of the tool.

The example of the standard cutter strategies evaluation is stated e.g. in [6]. Three various finishing strategies in machining of a shaped surface are compared under the same conditions. A surface texture, roughness and parameter accuracy were evaluated. The time of machining, the real one and from the simulation, was also compared. The work [7] deals with a design, evaluation and optimization of strategies as well. The author describes and evaluates the strategies for the roughing and finishing processes particularly. For roughing process he puts the emphasis on the biggest stock removal and the decrease of machining time, however at the same time the requirement is to create a consistent surface for the following finishing operations. In the strategy selection for the finishing operations, it is necessary to take into account on the one hand the shape, size and local curving of work-piece surfaces and on the other hand the shape and geometry of the tool. The strategies evaluation considering the machined surface quality and 
cutting forces is described in $[8,9]$ as well. Increasing the computer's performance the new strategies are developed based on the tool path generation using mathematic models. One approach, focused to minimizing the deviation from desired surface, is presented in [10]. The other one is based on special strategies focused to machining the specified type of shaped surface. The example is tool path generation for pocket machining with optimizing the federate as described in [11].

Despite complicated shapes of dies for their production, 3-axis milling operation is often sufficient [12]. It is caused by the way those tools are used during which a pressed material or a forged piece is needed to be removable from a die cavity without any problems. The direction of the pressed material removal is parallel with a cutter tool axis, manufacturing a surface of a dies. Slanted surfaces on side wall of die help to the remove of products.

The surface disparities, created after a technological operation, form the surface structure and therefore affect the surface functionality in the future. The surface structure is divided into parts according to the distance of relevant surface disparities. The part with the smallest distance creates the surface roughness, the part called the surface undulation and the part with the biggest distance set by the basic profile belongs there.

The surface roughness represents the disparities height of a real surface in regard to the perfect and ideal smooth-faced surface created by the complex of the surface disparities, with relatively small distances which are created as an inescapable result of a production technology or other effects. The surface faults (accidental irregular disparities occurring occasionally) and also various material faults, damages and others are not counted for this case.

Nowadays, the quantities, standardized in STN EN ISO 4287, are used for the evaluation of surfaces roughness. The calculation system, for the evaluation of parameters of a surface profile in terms of the stated norm, is based on the system of the middle line of the roughness profile, the undulation and the middle line of the primary profile. The evaluation of a surface roughness is implemented by the parameters of a roughness profile marked as $\mathrm{R}$. The roughness profile is derived from the basic profile by the compression of elements with a long wave longitude with the profile filter $\lambda \mathrm{c}$ and it creates the base for the evaluation of the roughness profile parameters. The evaluation of the surface roughness is possible with the profile method using contact profilomers. The method enables to detect the number values of standardized and nonstandardized characteristics of the surface micro-geometry. The method implementation is ensured by contact (point) devices - profilomers. The sharp point of a sensing device transfers a decomposition of disparities on a surface to a mechanical movement which is subsequently transferred, by the sensing device, to an electric signal and further elaborated and interpreted as the number value of the surface structure parameter which was selected, or eventually as a graphic record of the surface disparities profile.

The machined surface roughness is significantly influenced by the machining parameters. The feed optimizing at milling the shaped surface from the view of the final surface quality is described in $[13,14]$. One of the new approaches to the final surface evaluation, machined by ball mill, is described in [15]. Obtained 3D model of machined surface is connected to the machining parameters as well. Further enhancement of precision of evaluation is expected including the tool geometry to the analytic model. The influence of the tool shape and some parameters of milling strategies to surface roughness are also studied in [16]. The machined surfaces quality is not only evaluated by the surface roughness but their deviations of shape as well [17]. In present, the high attention is also paid to prediction of milling surface quality. The example of prediction model is presented in [17]. The prediction model presented in [19] comes 
out from CAD data and includes the tool geometry, pre-machined surface quality as well as the tool paths.

\section{Material and experimental methods}

The Fig. 1 shows the car body of car model that has been needed to stamp by stamping die. Considering the stamping punch has a shape of car body, the selected surfaces to measure and compare roughness are labeled as the roof, the front and the rear hood. The shape of stamping punch was derived from virtual CAD model of car body.

The experimental stamping die uses the stamping punch made out of Textit, also known as a Gumoid. It is a composite material reinforced by the cellulose paper and joined by phenolformaldehyde resin. Some material parameters of Textit are presented in Table 1 [20]. The selection of material has been determined by costs minimizing and rapid production.

Table 1 Material parameters of composite Textit [20]

\begin{tabular}{|ll|}
\hline Characteristics & Value \\
\hline \hline Specific density $\left[\mathrm{g} \cdot \mathrm{cm}^{-3}\right]$ & $1.3 \div 1.4$ \\
\hline Bending strength vertically to layers $[\mathrm{MPa}]$ & 110 \\
\hline Impact strength $\left[\mathrm{KJm}^{2}\right]$ & 7 \\
\hline Heat conductivity $\left[\mathrm{W} \cdot \mathrm{m}^{-1} \cdot \mathrm{K}^{-1}\right]$ & 0.2 \\
\hline Coefficient of thermal linear dilatability $\left[1 . \mathrm{K}^{-1} \cdot 10^{-6}\right]$ & $20 \div 40$ \\
\hline
\end{tabular}

At planning of stamping punch production five alternatives of different strategy has been proposed. The roughing operation was considered the same for all proposed strategies and contour strategy had been used. The strategy, tool and cutting conditions in roughing were chosen in order to maximization of material removal and cutting time shortening. The contour strategy was chosen the best one from available ones in software SolidCAM 2009. The finishing allowance $0.4 \mathrm{~mm}$ was left after roughing operation. Proposed alternatives differ by sequence of operations while the best one was chosen by virtual surface analysis and computed total production time.

The sequence of four operations has been used in the chosen alternative. After the roughing the second operation means finishing upper surfaces of stamping punch using parallel lining strategy. The Scallop Height of $0.005 \mathrm{~mm}$ was set up for this strategy. The third one operation is finishing of stamping punch side walls using strategy of constant $Z$. The same value of Scallop Height $0.005 \mathrm{~mm}$ was used for this strategy, but for step down the range of 0.01 to $0.2 \mathrm{~mm}$ was set. The final operation finishes the stamping punch body. In this operation any pre-finishing operations has been used. Considering the properties of composite Textit any relevant influence to final surface quality of stamping punch body has been assumed.

The end mill with diameter $\varnothing 10 \mathrm{~mm}$ has been used for roughing and the ball end mill with diameter $\varnothing 4 \mathrm{~mm}$ was used for finishing of upper surfaces and side walls. Because of specific material has been machined, cutting conditions were derived from recommended ones for materials of group $\mathrm{N}$. The cutting conditions were verified during workpiece preparation and adjusted to following ones:

- roughing: - cutting speed $\mathrm{vc}=106 \mathrm{~m} . \mathrm{min}-1$, feed per tooth $\mathrm{fz}=0.06 \mathrm{~mm}$,

- finishing: - cutting speed $\mathrm{vc}=62 \mathrm{~m} . \mathrm{min}-1$, feed per tooth $\mathrm{fz}=0.02 \mathrm{~mm}$. 
Machined stamping punch for experimental stamping die is shown in Fig. 2. Completed experimental stamping die has been try-out and set of stampings has been produced. As it is shown in Fig. 3, the segmentation in the shape of joined rectangle areas has been found out. The reason was insufficient tolerance of deviations $(0.01 \mathrm{~mm})$ for generated tool paths in regard of desired shape. This insufficiency has been removed at machining of production stamping punch by using the tighter tolerance of deviations. The optimal blank size and shape has been defined by testing the experimental stamping die as well.

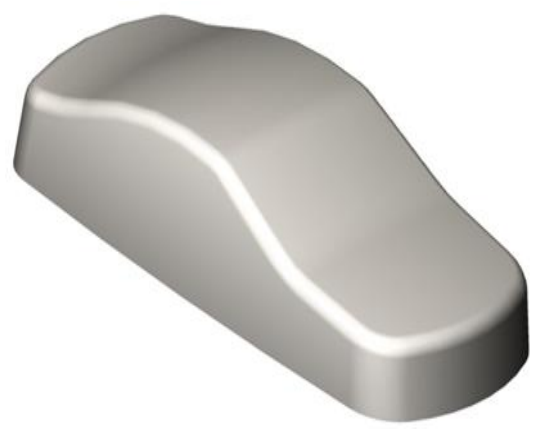

Fig.1 Car body model

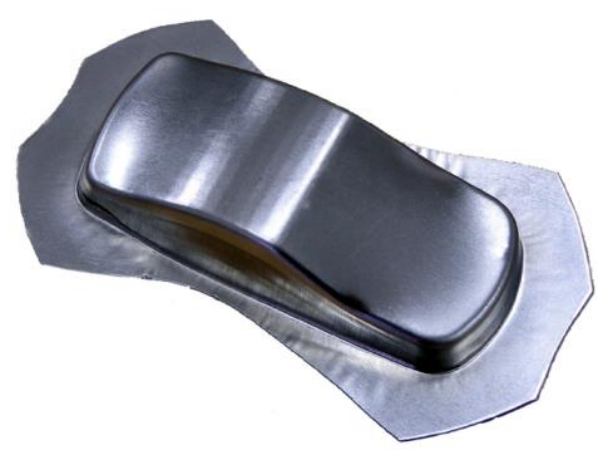

a)

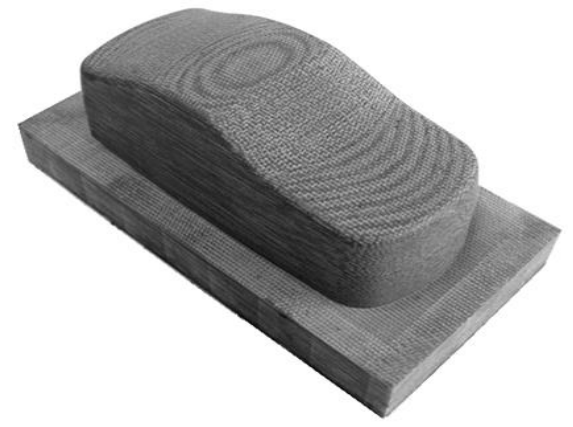

Fig.2 The stamping punch made out of Textit for experimental stamping die

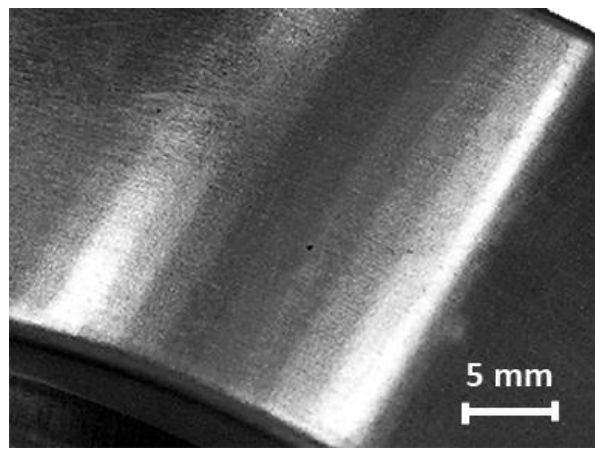

b)

Fig.3 The car-body stamping produced by experimental stamping die (a) with detailed view of segmented surface on the roof (b)

The production stamping punch is made out of the tool steel of X210Cr12 and the knowledge gained in production of experimental stamping die has been taken into considerations. The production process and used strategies has been approved and adopted with any changes. Considering machined material, pre-finishing operation of upper surfaces was included in production process. Its purpose was to uniform allowance before finishing to $0.02 \mathrm{~mm}$ value. The parameters of finishing operation were optimized as well. When finishing the upper surfaces using parallel lining strategy the scallop height of $0.005 \mathrm{~mm}$ and maximum side step of 0.15 $\mathrm{mm}$ were chosen. Finishing of side walls of stamping punch by constant $Z$ strategy was done using the same value of scallop height $0.005 \mathrm{~mm}$, but step down was changed to the range from 0.01 to $0.15 \mathrm{~mm}$. Tools were used the same as for production of experimental stamping punch 
made out of Textit. The cutting conditions were chosen by recommends of tool's producer for machined material as follows:

$$
\begin{aligned}
& \text { roughing: - cutting speed } \mathrm{v}_{\mathrm{c}}=80 \mathrm{~m} \cdot \mathrm{min}^{-1} \text {, feed per tooth } \mathrm{f}_{\mathrm{z}}=0.09 \mathrm{~mm} \text {, } \\
& \text { finishing: - cutting speed } \mathrm{v}_{\mathrm{c}}=40 \mathrm{~m} \cdot \mathrm{min}^{-1} \text {, feed per tooth } \mathrm{f}_{\mathrm{z}}=0.02 \mathrm{~mm} \text {. }
\end{aligned}
$$

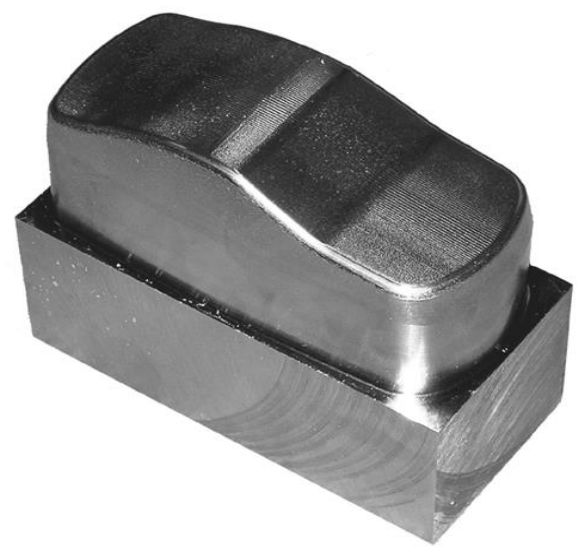

Fig.4 The stamping punch made out of tool steel of X210Cr12 for production stamping die

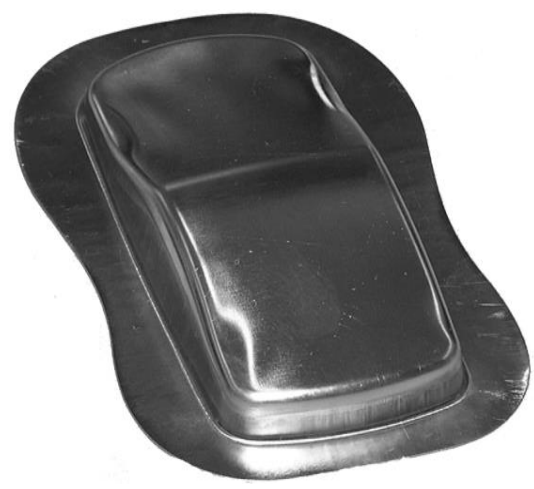

a)

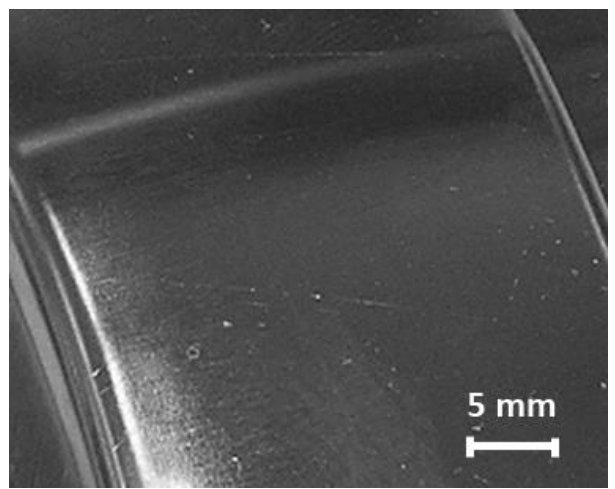

b)

Fig.5The car-body stamping produced by production stamping die (a) with detailed view of smooth surface on the roof (b)

The stamping punch of production stamping die is shown in Fig. 4. The smooth surface of stamping without any segmentation, as it is shown in Fig. 5, has been achieved by using the tighter tolerance of deviations for tool paths generation.

Machining of experimental and production stamping punches was performed on 3-axis CNC machine Emco Mill 155. Production times were the same as calculated ones by numerical simulations in CAM software.

The roughness of final surfaces in selected areas of stamping punch was done using profilometer Surftest SJ-301 by Mitutoyo. The equipment works on principle of surface scanning by diamond-point sensing head with radius $5 \mu \mathrm{m}$ placed on sprung arm.

The parameters for surface roughness measurement were chosen based on the standard STN EN ISO 4287 as follows: 
- $\lambda \mathrm{c}$ profile filter $-0.8 \mathrm{~mm}$,

- number of basic lengths $\mathrm{N}=5$,

- measured profile: R (median line system),

- filter: Gauss,

- $\quad$ evaluated length $\ln =4 \mathrm{~mm}$.

As measured parameters in terms of the standard STN EN ISO 4287 were chosen:

- $\mathrm{Ra}$ - arithmetical mean deviation of the assessed profile,

- $\mathrm{Rz}$ - maximum height of profile.

Measured areas of machined surfaces were also documented by microscope with sensing camera and 30-times magnification. Microscope Mitutoyo was installed on positioning unit of Surftest profilometer.

\section{Results and evaluation}

Roughness parameter $\mathrm{Ra}$ (arithmetical mean deviation) is the basic and the most common evaluated parameter to describe surface microgeometry. But, when two surfaces are evaluated by $\mathrm{Ra}$ parameter, the same value of Ra might point to different surface morphology. Therefore, it necessary to use the other one roughness characteristic to differ evaluated surfaces more accurately. So, the $\mathrm{Rz}$ (maximum height of profile) has been chosen that is considered as comparable one to Scallop Height (SH) needed to set up in CAD systems [21].

Table 2 Comparison of surface textures and roughness values for experimental materials

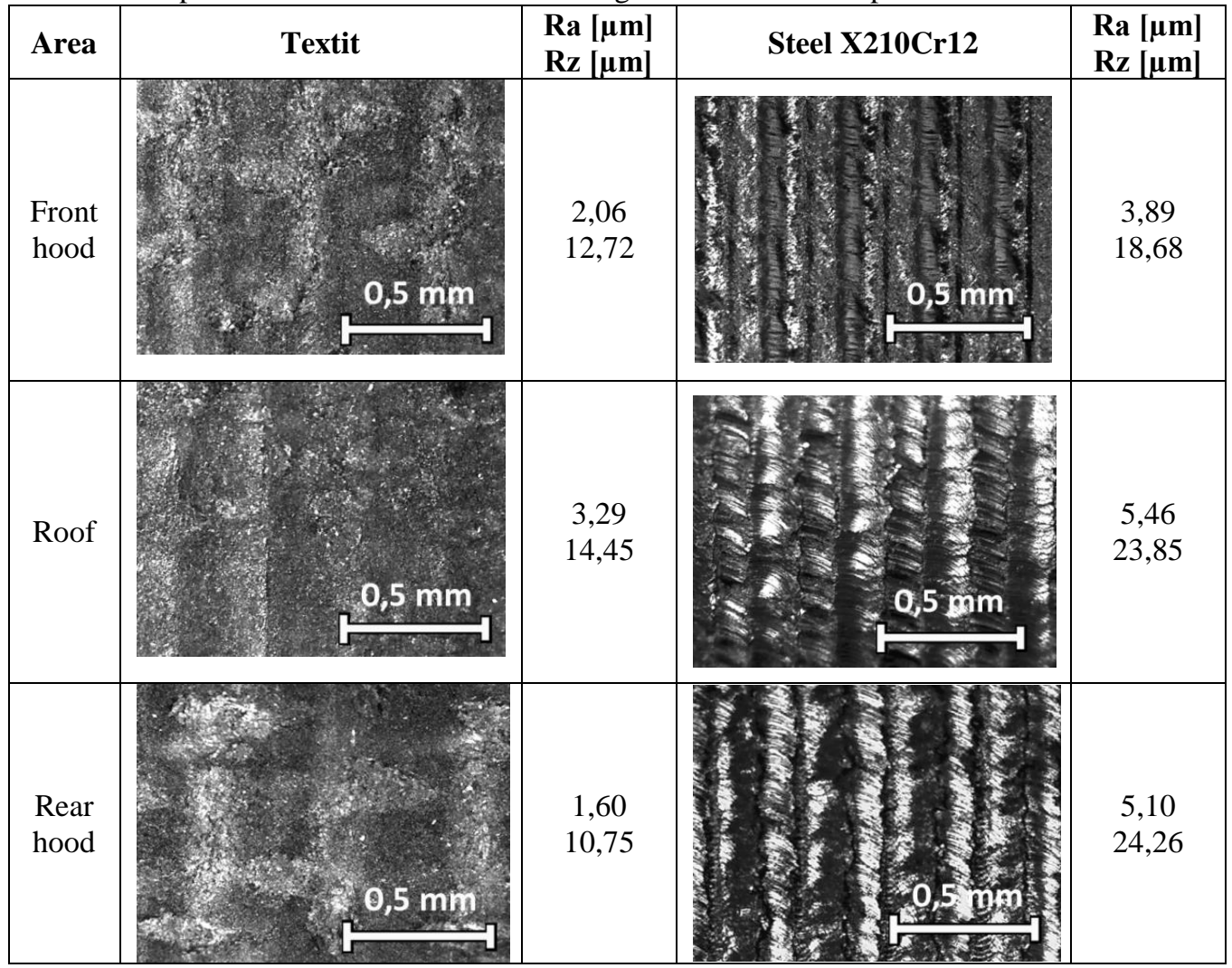


Detailed views on areas of top surface of experimental stamping punch made out of Textit are shown in Table 2 on the left. These areas (the front hood, the roof, the rear hood) have been machined using parallel lining strategy that generates tool path in parallel 2D plains oriented vertical. Tool tracks are weak, but periodic and oriented parallel. The surface roughness measured in these areas was from $\mathrm{Ra} 1.60 \mu \mathrm{m}$ to $\mathrm{Ra} 3.9 \mu \mathrm{m}$, or $\mathrm{Rz} 10.75 \mu \mathrm{m}$ to $\mathrm{Rz} 14.45 \mu \mathrm{m}$. Layered cellulose paper coming out to surface is shown on detailed view in lighter areas.

The right side of the Table 2 presents detailed views on areas of top surface of production stamping punch made out of the tool steel. Tool tracks on top surfaces are periodic and oriented parallel as well. The roughness $\mathrm{Ra}$ was in the range of $3.89 \mu \mathrm{m}$ to $5.46 \mu \mathrm{m}$, or $\mathrm{Rz} 18.68$ to 24.26 $\mu \mathrm{m}$.

The graph shown in Fig. 6 compares measured values of arithmetical mean value Ra and maximum height of profile $\mathrm{Rz}$ to scallop height $\mathrm{SH}$ for surface of experimental stamping punch made out of composite Textit. The SH value has been set in CAM system the same for all finishing strategies. Measured values of $\mathrm{Rz}$ reached from 2.15 to 2.89 multiplication of defined scallop height. $\mathrm{Rz}$ value is closest to $\mathrm{SH}$ value on the rear hood, the maximum difference is on the roof.

The graph shown in Fig. 7 compares measured values of arithmetical mean value Ra and maximum height of profile $\mathrm{Rz}$ to scallop height $\mathrm{SH}$ for surface of production stamping punch made out of tool steel X210Cr12. The SH value set in CAM system was the same for all finishing strategies too. Measured values of $\mathrm{Rz}$ reached from 3.74 to 4.85 multiplication of defined scallop height. $\mathrm{Rz}$ value is closest to $\mathrm{SH}$ value on the front hood, the maximum difference is on the rear hood.

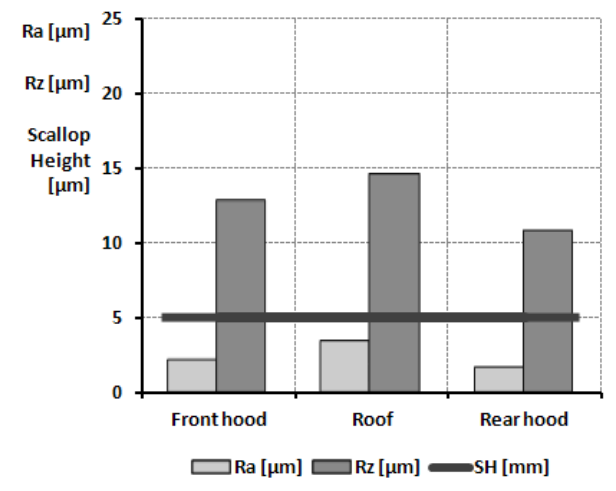

Fig.6Comparison $\mathrm{Ra}$ and $\mathrm{Rz}$ roughness to scallop height $\mathrm{SH}$ for experimental stamping punch made out of composite Textit

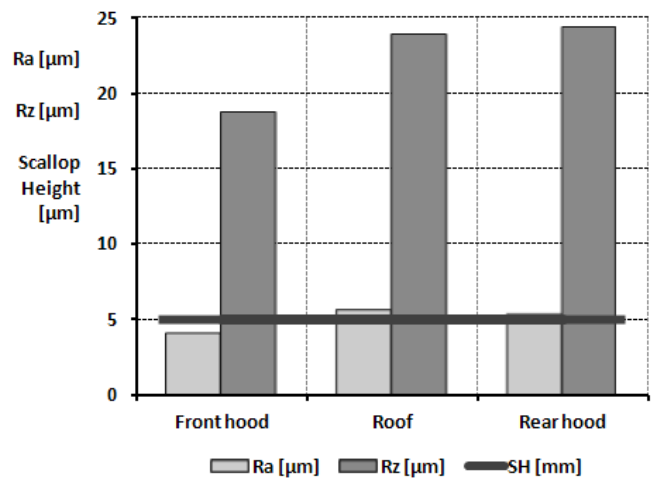

Fig.7 Comparison $\mathrm{Ra}$ and $\mathrm{Rz}$ roughness to scallop height $\mathrm{SH}$ for production stamping punch made out of steel $\mathrm{X} 210 \mathrm{Cr} 12$

Based on realized experiments and measured values of final surface roughness following outputs were observed:

1. Knowledge gained during production of experimental punch from Textit allowed optimizing strategy and final surface quality to desired values for production stamping punch in short production time and low production costs. They also affected final surface quality of production stamping punch as well as the stamping. The good 
manufacturability and machineability of Textit has been gained and verified as the very important knowledge as well.

2. The experimental stamping punch was used to verify deep drawing of car body in experimental drawing die and to define desired blank shape. The experimental material Textit has been proved as a material suitable for rapid tooling as well as rapid optimization of deep drawing process.

3. Comparing measured values of roughness in defined areas of stamping punch the higher values of $\mathrm{Ra}$ and $\mathrm{Rz}$ were measured when punch was produced from tool steel $\mathrm{X} 210 \mathrm{Cr} 12$. It is given by the different machineability of these materials. The higher cutting forces are when steel is machined, so the requests for toughness of machinetool-workpiece system arise as well. Using the same elements of machine-toolworkpiece system at machining of composite and tool steel brought along the worse surface quality of stamping punch made out of tool steel.

4. The measured $\mathrm{Rz}$ values for both stamping punches were higher than Scallop Height value set up in CAM system. The common equations for the roughness calculation account basic factors only, such as tool diameter, tool path spacing and allowance size. But, the surface roughness is affected by the wide range of factors. The accuracy of mathematic model used in CAM system depends on the number and the importance of these factors as well.

\section{Conclusions}

The aim of the experiments was to verify production of complex shape surface, such as the stamping punch of experimental and production stamping dies. These stamping punches have been made out of two materials - composite Textit and steel X210Cr12. During experiments machining strategies as well as cutting conditions of stamping punch production have been optimized to reach desired surface quality. Comparing $\mathrm{Ra}$ and $\mathrm{Rz}$ values to the value of Scallop Height the differences have been observed for both materials. Therefore, the research these phenomena and further specification of mathematic models used in CAM system is necessary as well.

\section{References}

[1] Project of tin car for Steelpark. [online]. Košice: TU, SjF [cit. 2013-08-17]. Accessible on the internet < http://www.sjf.tuke.sk/ktam/steelpark/>

[2] Z. C. Chen, D. Song: Journal of Manufacturing Processes, Vol. 8, 2006, No. 1, p. 29-38, DOI:10.1016/S1526-6125(06)70099-8

[3] H.L. Lee, M.S. Park, M.T. Kim, C.N. Chu: International Journal of Machine Tools \& Manufacture, Vol. 46, 2006, No. 9, p. 1027-1034, DOI: 10.1016/j.ijmachtools.2005.07.049

[4] A. Curodeau, M. Richard, L. Frohn-Villeneuve: Journal of Materials Processing Technology, Vol. 149, 2004, No.1-3, p. 278-283, DOI: 10.1016/j.jmatprotec.2003.10.040

[5] E.J. Wei, M.C. Lin: Journal of Materials Processing Technology, Vol. 168, 2005, No.3, p. 408-413, DOI: 10.1016/j.jmatprotec.2004.11.009

[6] A. M. Ramos, C. Relvas, J. A. Simões: Journal of Materials Processing Technology, Vol.136, 2003, No. 1 - 3, p. 209-216, DOI: 10.1016/S0924-0136(03)00160-2

[7] C. K. Toh: Materials and Design, Vol. 26, 2005, No. 6, p. 517-533, DOI:10.1016/j.matdes.2004.07.019 
[8] M. Kaymakci, I. Lazoglu: Machining Science and Technology, Vol. 12, 2008, No. 1, p.119132, DOI: $10.1080 / 10910340801913979$

[9] H. Perez, E. Diez, J. Perez, A. Vizan: Procedia Engineering, Vol. 63, 2013, No. 1, p.573581, DOI: 10.1016/j.proeng.2013.08.193

[10]A. Jaganathan, Y. J. Lin: Advanced Manufacturing Technology, Vol. 21, 2003, No. 9, p.627-636, DOI: 10.1007/s00170-002-1383-2

[11] V. Pateloup, E. Duc, P. Ray: International Journal of Machine Tools \& Manufacture, Vol. 44, 2004, No. 12-13, p. 1343-1353, DOI: 10.1016/j.ijmachtools.2004.04.011

[12] V. Šimna, P. Pokorný: MM Science Journal, Vol. 6, 2013, No. 2, p. 410-414.

[13]D. K. Baek, T. J. Ko, H. S. Kim: International Journal of Machine Tools \& Manufacture, Vol. 41, 2001, No. 3, p. 451-462, PII: S 0890-6955(00)00039-0

[14]K. Erkorkmaz, S.E. Layegh, I. Lazoglu, H. Erdim: CIRP Annals - Manufacturing Technology, Vol. 62, 2013, No.1, p. 395-398, DOI: 10.1016/j.cirp.2013.03.084

[15] Y. Quinsat, L. Sabourin, C. Lartigue: Journal of materials processing technology, Vol. 195, 2008, No. 1 - 3, p. 135-143, DOI: 10.1016/j.jmatprotec.2007.04.129

[16] J. Senatore, S. Segonds, W. Rubio, G. Dessein: Application to milling by zones, Vol. 44, 2012, No. 12, p. 1151-1160, DOI: 10.1016/j.cad.2012.06.008

[17] K. A. Desai, P. V. M. Rao: Journal of Materials Processing Technology, Vol. 212, 2012, No. 11, p. 2443-2454, DOI:10.1016/j.jmatprotec.2012.07.003

[18] A. M. Zain, H. Haron, S. Sharif: Expert Systems with Applications, Vol. 37, 2010, No. 2, p. 1755-1768, DOI: 10.1016/j.eswa.2009.07.033

[19]N. Zeroudi, M. Fontaine: Procedia CIRP, Vol. 1, 2012, No. 1, p. 108-113, DOI:10.1016/j.procir.2012.04.017

[20] Characteristic of Textit (Gumoid). [online]. Ostrava: Hansanet [cit. 2013-07-22]. Accessible on the internet <http://www.rempo.cz/clanek/33/Charakteristika-TEXTIT-(-Gumoid).aspx>

[21] J. Stahovec, J. Beňo, M. Vrabel': Investigation of the cusp height when ball-end milling form shaped surfaces. International scientific conference Progressive Technologies and Materials, Bezmiechowa, Poland, 2013, p. 234 - 240

\section{Acknowledgement}

Authors express their thanks for projects VEGA 1/0500/12 "Quality improvement when milling form surfaces by advanced milling tools" and VEGA 1/0396/11 "Research and optimization of methods for evaluation strength and plastic parameters of very thin tin steel sheets" supported by Scientific Grant Agency of the Ministry of Education, Science and Research of Slovakia. 